The neural mechanisms underlying behavioral variation among individuals are not well

3 understood. Differences among individuals in sensory sensitivity could limit the environmental stimuli to

4 which an individual is capable of responding and have, indeed, been shown to relate to behavioral

5 differences in different species. Here, we show that ant workers in Temnothorax rugatulus differ

6 considerably in the number of antennal sensory structures, or sensilla (by $45 \%$ in density and over $100 \%$ in

7 estimated total number). A larger quantity of sensilla may reflect a larger quantity of underlying sensory

8 neurons. This would increase the probability that a given set of neurons in the antenna detects an

9 environmental stimulus and becomes excited, thereby eliciting the expression of a behavior downstream at

10 lower stimulus levels than an individual with comparatively fewer sensilla. Individual differences in

11 antennal sensilla density, however, did not predict worker activity level or performance of any task,

12 suggesting either that variation in sensilla density does not, in fact, reflect variation in sensory sensitivity or

13 that individual sensory response thresholds to task-associated stimuli do not determine task allocation as is

14 commonly assumed, at least in this social insect. More broadly, our finding that even closely related

15 individuals can differ strongly in peripheral sensory organ elaboration suggests that such variation in

16 sensory organs could underlie other cases of intraspecific behavioral variation.

18 Keywords: Social insects, response thresholds, sensilla, task allocation, behavioral variation

\title{
20 INTRODUCTION
}

21 Consistent inter-individual behavioral differences are nearly ubiquitous in animals (e.g. in arthropods

22 (Pruitt et al., 2008), fish (Bell and Sih, 2007), mammals (Gosling, 1998)). Still, little is known about the

23 fundamental neural mechanisms underlying them. Social insects provide a convenient model system for

24 this question because nestmates exhibit stable, inter-individual differences in behavior by specializing on

25 particular tasks. Often, nestmates vary considerably in overall activity level as well (e.g. Charbonneau et

26 al., 2014; Jandt et al., 2012). Such division of labor (in both task and activity level) emerges without any

27 leader and may rely on intrinsic variation in task preference among workers (Beshers and Fewell, 2001), 
28 learned differences (e.g. Ravary et al., 2007), or social signals (e.g. Greene and Gordon, 2007; Pinter-

29 Wollman et al., 2011).

30 Here, we investigate whether fixed differences at the level of the peripheral nervous system,

31 specifically in the number of antennal sensory structures, contribute to behavioral variation among social

32 insect workers. We base this idea on a widely accepted hypothesis explaining division of labor in social

33 insects (both task specialization and overall activity level), which invokes variable response thresholds to

34 task-related stimuli: if workers differ in the levels of task-related stimuli they respond to, this may lead to

35 differences in how often a task is performed (Beshers and Fewell, 2001). Most studies have assumed these

36 'thresholds' generally arise in the central nervous system (CNS) and therefore limit their scope to the brain

37 (reviewed in Kamhi and Traniello, 2013; Page and Robinson, 1991). However, variation in sensory organ

38 size, development, or innervation could also directly lead to different response thresholds by limiting or

39 biasing sensory information before it even reaches the brain.

40 A possible role for the peripheral nervous system in worker behavioral differences is supported by

41 findings that differences in olfactory receptor expression, for example, are associated with behavioral

42 receptivity to odor stimuli in honeybees (Villar et al., 2015). In addition, variation in the number of

43 antennal sensory organs (sensilla) is linked to olfactory acuity in bumblebees (Spaethe et al., 2007), forager

44 resource preferences in honeybees (Riveros and Gronenberg, 2010) and aggression level in weaver ants

45 (Gill et al., 2013). Whether such peripheral mechanisms underlie social insect response thresholds that

46 drive division of labor in a broader context (i.e. across all tasks) is unclear. Here, we use the brown rock ant

47 Temnothorax rugatulus to quantify inter-individual variation in the number of particular functional types of

48 antennal sensilla and test the hypothesis that differences in sensilla number predict activity level and/or task

49 allocation. T. rugatulus workers show pronounced differences in activity level and are weakly specialized

50 in different tasks (Charbonneau and Dornhaus, 2015; Charbonneau et al., 2017; Pinter-Wollman et al.,

51 2012). If sensilla number corresponds to higher sensory sensitivity, and thus affects task-associated

52 response thresholds, we expect that ants with more sensilla will be (1) more active overall and/or (2) more

53 active or specialized in particular tasks that are likely to depend on chemical sensitivity, such as foraging

54 (an outside task conducted in a complex sensory environment) and brood care (Vander Meer and Alonso;

55 1998, Conte and Hefetz, 2008). 
57 METHODS

58 Six queen-right $T$. rugatulus colonies were collected November 2014 - October 2016 from the Santa

59 Catalina Mountains, Tucson, AZ, at an elevation of $2134 \mathrm{~m}$. Colony sizes ranged from 14 to 55 workers.

60 Each colony was housed in an artificial nest consisting of a cardboard nest chamber between two glass

61 slides and kept inside a fluon-coated container, as described by (Charbonneau et al., 2014). Ants were

62 provided freeze-killed fruit flies, honey solution and water ad libitum and kept on a $12 \mathrm{~h}$ light cycle at $21^{\circ}$

63 C. Each ant was individually marked using Testor’s Pactra® paint.

64 We measured worker behavior using one of two protocols: (1) filming whole colonies for five

65 minutes at arbitrary timepoints between 8 am and $5 \mathrm{pm}$ on three days within a two-week period, or (2)

66 filming whole colonies for 10 minutes at arbitrary times between 8 am and $5 \mathrm{pm}$ on four days in a one week

67 period. The behavioral state (see Table 1) of each ant was recorded every second by an observer analyzing

68 all three videos. Therefore, for each colony 3 sessions were filmed and analyzed. Activity level for each

69 worker was measured as the proportion of time each ant was not 'inactive' (motionless and apparently not

70 working). Task specialization was measured in two ways: as (1) proportion of total time and (2) proportion

71 of active time each ant spent in the focal behavioral state. Immediately following the final filming session

72 for each colony, ants were fixed in alcoholic Bouin's fixative (formaldehyde, picric acid, acetic acid) then

73 washed with $70 \%$ ethanol. We quantified elaboration of the peripheral sensory organs by counting the

74 number of sensillum insertions ('sockets', hereafter also referred to as 'sensilla') on the distal-most

75 segment of the right antenna of each worker. T. rugatulus ants have club-shaped antennae in which the

76 distal-most segment comprises by far the highest number of sensilla (Ramirez-Esquivel et al., 2017). If the

77 right antenna was damaged, we instead used the left antenna since sensilla number is bilaterally

78 symmetrical (Online Resource 1). To visualize under the light microscope, antennae were incubated in

$79100 \%$ ethanol at $25^{\circ} \mathrm{C}$ for ten minutes and then in methyl salicylate for sixty minutes. Antennae were then

80 mounted onto slides using methyl salicylate, sealed under a cover slip with nail polish and viewed under a

$8163 \mathrm{x} / 1.25$ Plan-Neofluoar oil objective using a Zeiss Axioplan brightfield microscope. We used SPOTbasic

82 software to capture images of the dorsal and ventral surfaces of the distal-most segment and the GNU

83 image manipulation program GIMP 2.8 to count sensilla sockets within a defined area $(100 \mu \mathrm{m} \times 50 \mu \mathrm{m})$ 
84 covering most of the segment and aligned with the base of the segment on both surfaces. We approximated

85 total sensilla number by estimating the distal-most segment surface area using the equation of a cylinder

$86(2 \pi r h)$ for $70 \%$ of the segment's length and a circular cone $(\pi r l)$ for $30 \%$ of its length (resembling the

87 approximate shape of the antennal segment). Ants with missing or damaged antennae were discarded,

88 leaving us with a total sample size of 150 ants.

89 Socket size was used to differentiate between thinner sensilla with smaller sockets and thicker

90 sensilla with larger sockets. The "small-socket" group broadly included sensilla chaetica

91 (mechanoreceptors, Dumpert, 1972a), coeloconica (responsive to temperature change, Ruchty et al., 2009),

92 trichoidea (putative contact chemoreceptors, Hashimoto, 1990) and trichoidea-II (unknown function,

93 previously described in ants by Nakanishi et al., 2009; Ramirez-Esquivel et al., 2014) (Figure 1a, white

94 arrows). The "large-socket" group included two chemosensitive sensilla types: sensilla basiconica (contact

95 chemoreceptors, thought to be involved in nestmate recognition, Renthal et al., 2003; Sharma et al., 2015)

96 and trichoidea curvata (detection of volatile compounds, e.g. pheromones, Dumpert, 1972b) (Figure 1a,

97 black arrows). Sensilla ampullacea, sensitive to carbon dioxide (Kleineidam et al., 2000) were quantified

98 by counting the distinctive peg-like structures located within the lumen of the distal-most antennal segment

99 (Figure 1b). Absolute number was used instead of density in this case because sensilla ampullacea are

100 clustered in one area of the segment. For 32 samples, air bubbles that remained in the lumen made counting

101 of the internal sensilla impossible. For this analysis, therefore, we had a total sample size of 118 ants.

102 Antenna size was assessed by measuring the length of the distal-most antennal segment using a stage

103 micrometer and Image $\mathrm{J}^{\circledR}$ software.

104

105 Statistical analyses

106 We used a linear model to test the hypothesis that sensilla density is associated with task allocation,

107 specifically the proportion of time spent performing different tasks. A linear model was also used to assess

108 the relationship between different (i.e. small and large-socket) sensillum types and their association with

109 the surface area of the distal-most antennal segment. Colony was incorporated as a random factor for all

110 linear models. We used a non-parametric Kruskal-Wallis test for determining the relationship between the

111 surface area of the distal-most antennal segment and number of sensilla ampullacea, which had discrete 
112 values of 3, 4, 5 or 6 sensilla and was not normally distributed. All statistical analyses were performed in $\mathrm{R}$

$113 \quad 2.15 .1$, using lme4 and base 'stats' packages.

114

115 RESULTS

116 Variation across workers

117 Antennal sensilla density and absolute sensilla number varied considerably among workers across colonies

118 (Figure 2a, b). Within colonies sensilla density and total sensilla number also varied among nestmates

119 (average coefficient of variation in sensilla density $=0.064$, absolute number $=0.100$ ).

120

\section{Variation in sensilla types and total sensilla number}

122 Small and total sensilla density decreased with increasing surface area of the distal-most antennal segment

123 (Figure 3), indicating that ants with larger antennae do not have proportionately more (small) sensilla. The

124 shallow slope of the trend lines, however, suggests that larger ants, on average, still have more sensilla than

125 smaller ants. In addition, as total sensilla density increased, both small-socket sensilla (on average $85 \%$ of

126 total) and large-socket sensilla (15\% of total) increased (Figure 4). Ants with more small-socket sensilla,

127 however, had fewer large-socket sensilla (Figure 5). Though contributing less to overall number, large-

128 socket sensilla density varied more than small-socket sensilla (coefficient of variation: small-socket sensilla

$129=0.084$ and large-socket sensilla $=0.22$ ). The number of $\mathrm{CO}_{2}$-sensitive sensilla ampullacea was much

130 lower than that of the other two types and did not correlate with surface area of the distal-most antennal

131 segment (coefficient of variation $=0.14$; Figure 6 ). There was no relationship between the number of

132 sensilla ampullacea and total sensilla density (Online Resource 2).

133

134 Sensilla density and worker behavior

135 The quantitative differences we observed in the number of sensory units (presumably reflecting the number

136 of underlying sensory neurons) should be associated with differences in sensory sensitivity and, according

137 to the response threshold hypothesis, response thresholds and worker behavior (Chapman, 1982; Spaethe et

138 al., 2007). However, we found no relationship between individual worker sensilla density and activity level

139 (Figure 7a). Sensilla density was also not associated with any specific tasks, whether calculated as 
140 proportion of total time (Figure 7; Table 2) or active time (Table 2; Online Resource 3). No relationship

141 was found when using any of the specific sensilla types (Online Resource 4). Similarly, antennal surface

142 area (i.e. antenna size) did not predict worker performance in any task (Table 2; Online Resource 5). None

143 of these analyses changed qualitatively if only ants from the first or second filming protocol were used.

\section{DISCUSSION}

146 We find considerable variation across workers in the density and total number of sensory

147 structures on the antenna. Total sensilla density and small-socket sensilla density decrease slightly with

148 increasing antenna size, while variation in large-socket sensilla density is not associated with antenna size.

149 Interestingly, ants with higher small-socket sensilla density tend to have lower large-socket sensilla density,

150 suggesting the possibility that these two sensilla types might trade off against each other. The number of

151 sensilla ampullacea is much smaller (between 3-6) and appears to stay constant across antennal surface

152 areas and sensilla densities. This result supports earlier findings in other ant species in which the number of

153 ampullacea is stable across workers. In the very large ant Atta sexdens, workers have about 10 sensilla

154 ampullacea within the distal-most antennal segment (Kleineidam et al., 2000), while the moderately sized

155 Myrmecia pyriformis workers have far more ampullacea, between 21-24 (Ramirez-Esquivel et al., 2014).

156 Apparently, then, ampullacea number does not covary with worker size either within or across species. This

157 raises interesting questions about how differences in these species' natural histories (e.g. nesting habits) has

158 led to different stabilizing selection pressures on $\mathrm{CO}_{2}$-sensitive sensilla.

159 Despite the large variation in total sensilla density across individual workers, this was not

160 associated with task allocation or activity level in T. rugatulus. Given our result, variation in sensilla

161 density must either (1) not significantly affect sensory sensitivity or (2) performance in most tasks must not

162 be predicted by sensory sensitivity, at least in T. rugatulus. The lack of a relationship between sensilla

163 density and any of the tasks we measured is puzzling given that earlier work had established a link between

164 sensilla number and differences in behavior, sensitivity and even learning in some social insects (Gill et al.,

165 2013; Riveros and Gronenberg, 2010). Larger bumblebee workers, for example, have more sensilla and

166 lower response thresholds to a conditioned olfactory stimulus (Spaethe et al., 2007). However, it appears

167 that the functional consequence of sensory organ variation is far from obvious and perhaps cannot be 
168 generalized across species, or even across tasks within the same species. Recent work in Pheidole ants, for 169 example, demonstrates that unilateral antennal ablation (i.e. resulting in the loss of roughly half of their 170 sensilla) does not prevent workers from carrying out most of their normal task repertoire (Waxman et al., 171 2017). In contrast, antennal removal has significant effects on behavior in Tetragonula bees (though this 172 was not associated with sensilla number), and in honeybees the right antenna is both more enriched with 173 olfactory sensilla and better at recalling olfactory memories than the left. Yet, in this same species, the 174 peripheral nervous system is not associated with worker differences in responsiveness to alarm pheromone 175 (Robinson, 1987). Though we do find variation in T. rugatulus sensory organs, our results are consistent

176 with those of (Waxman et al., 2017), which suggest that sensory organ differences may not have significant 177 effects on behavior and task allocation. Rather than variation in density, variation in the size of individual 178 sensilla or differences across individual sensilla in the number of underlying sensory neurons might affect 179 sensory sensitivity and therefore behavior. If this were the case, quantifying sensilla number or density 180 would not capture the true functional variation in sensory organs among workers, a possibility that deserves 181 further investigation. Alternatively, our results might indicate that the central nervous system, alone, drives 182 response thresholds. In this case, the central nervous system would have to impose a great enough amount 183 of variation to override the considerably large differences we observed in the periphery.

184 A second possibility is that differences sensitivity (i.e. response thresholds) are not the driving 185 force for division of labor as is commonly thought for social insects. Though response thresholds are very 186 well established in honeybees (e.g. Page et al., 1998; Pankiw and Page, 2000) empirical evidence for their 187 existence and role in division of labor in other social species is sparse and sometimes conflicting. In 188 bumblebees, for example, workers differ in fanning thresholds for temperature and $\mathrm{CO}_{2}$, however these 189 thresholds do not predict the probability that a worker will fan or how long it will fan (Weidenmüller, 190 2004). If our assumption that sensilla density variation reflects sensitivity variation is correct, then our 191 results would suggest that response thresholds are not governing division of labor in T. rugatulus ants and 192 are therefore not a universal driver of social insect division of labor. In summary, a $45 \%$ difference in 193 individual sensory organ elaboration that has no effect on task performance suggests one of two possible 194 conclusions: (1) either sensory organ elaboration is not associated with sensory sensitivity, in which case 195 sensilla may not be costly to produce and/or maintain and are therefore under low selection pressure to 
196 eliminate unnecessary variation; or (2) differences in sensitivity to task-relevant stimuli (i.e. response

197 thresholds) may not be a driver of task allocation in this social insect. To better understand mechanisms by

198 which division of labor specifically, and inter-individual behavioral variation in general, is created further

199 investigations should attempt to distinguish between these two alternatives.

200

201 TABLES AND FIGURES

202 Table 1 Different behavioral states used to determine task allocation. No other tasks were observed 203

204 Table 2 Sensilla socket density does not predict time spent performing any tasks after Bonferroni

205 correction for multiple comparisons (adjusted $\alpha \leq 0.008$ ). Similarly, the surface area of the distal-most

206 antennal segment does not predict task specialization. Shown above are the results of linear mixed effects

207 models based on proportion of total time spent performing each focal task and proportion of active time

208 spent performing each focal task. Random effect: colony, $\mathrm{n}=150$ ants, 6 colonies

209

210 Fig. 1 The distal-most antennal segment of a T. rugatulus worker showing (a) sensilla sockets (black

211 arrows: large sockets, white arrows: small sockets); and (b) invaginated sensilla ampullacea (black arrows).

212 Scale bar: $100 \mu \mathrm{m}$

213

214 Fig. 2 Sensilla density (a) and absolute sensilla number (b) varies among T. rugatulus workers (density:

$215 \min =0.0062$ sensilla $/ \mu \mathrm{m}^{2}, \max =0.0096$ sensilla $/ \mu \mathrm{m}^{2} ;$ absolute number: $\min =377$ sensilla, $\max =798$

216 sensilla, $\mathrm{n}=150$ ants, 6 colonies)

217

218 Fig. 3 Both total and small-socket sensilla density decrease with increasing surface area of the distal-most

219 antennal segment. Large-socket sensilla density, however, varies independently of surface area. Blue

220 triangles: total sensilla socket density (linear mixed effects model p-value $<0.0001$, random effect: colony,

221 fixed effect: sensilla density, slope $\left.=-2.04 \times 10^{-8}\right)$; Red open circles: small sensilla socket density (linear

222 mixed effects model $\mathrm{p}$-value $<0.0001$, random effect: colony, fixed effect: sensilla density, slope $=-2.07 \mathrm{x}$ 
$22310^{-8}$ ); Green: large sensilla socket density (linear mixed effects model p-value $=0.18$, random effect:

224 colony, fixed effect: sensilla density, $\mathrm{n}=150$ ants, 6 colonies)

225

226 Fig. 4 As total sensilla density increases, (a) small-socket and (b) large-socket sensilla increase. No

227 statistics are reported here because variables are not independent of one another. Graphs serve to simply

228 illustrate the relationship between different sensilla types and total sensilla density. Each colony is

229 represented by a different color and shape, $\mathrm{n}=150$ ants, 6 colonies

230

231 Fig. 5 Ants with a higher density of small-socket have a lower density of large-socket sensilla, suggesting

232 that these two sensilla types trade off against one another (Linear mixed effects model $p$-value $=0.03$,

233 random effect: colony, fixed effect: large sensilla density, slope $=-0.07, \mathrm{n}=150$ ants, 6 colonies

235 Fig. 6 The number of sensilla ampullacea $\left(\mathrm{CO}_{2}\right.$-sensitive sensilla) on the distal-most antennal segment is

236 not associated with the surface area of that segment. Kruskal-Wallis p-value $=0.48, \mathrm{n}=118$ ants, 6

237 colonies. Boxplot shows the lower and upper quartiles (box), median (horizontal line in box), and extremes

238 (whiskers) for antennal surface area associated with each number of sensilla ampullacea

240 Fig. 7 Individual worker sensilla density does not predict proportion of total time spent performing any task

241 (a-e). Different colors/shapes represent different colonies. Statistics summarized in Table 2, $\mathrm{n}=150$ ants, 6

242 colonies

\section{REFERENCES}

Bell, A.M., Sih, A., 2007. Exposure to predation generates personality in threespined sticklebacks (Gasterosteus aculeatus). Ecol Letters 10, 828-834. doi:10.1111/j.1461-0248.2007.01081.x 413-440. doi:10.1146/annurev.ento.46.1.413 Treherne, J.E., Wigglesworth, V.B. (Eds.), Advances in Insect Physiology, Advances in Insect Physiology. Academic Press, pp. 247-356.

Charbonneau, D., Dornhaus, A., 2015. Workers "specialized" on inactivity: Behavioral consistency of inactive workers and their role in task allocation. Behav Ecol Sociobiol 69, 1459-1472. doi:10.1007/s00265-015-1958-1

Charbonneau, D., Hillis, N., Dornhaus, A., 2014. 'Lazy' in nature: ant colony time budgets show high 'inactivity' in the field as well as in the lab. Insect. Soc. 62, 31-35. doi:10.1007/s00040-014-0370-6 
Charbonneau, D., Poff, C., Nguyen, H., Shin, M.C., Kierstead, K., Dornhaus, A., 2017. Who Are the "Lazy" Ants? The Function of Inactivity in Social Insects and a Possible Role of Constraint: Inactive Ants Are Corpulent and May Be Young and/or Selfish. Integrative and Comparative Biology 57, 649667. doi:10.1093/icb/icx029 542. doi:10.1146/annurev.ento.52.110405.091434

Dumpert, K., 1972a. Bau und verteilung der sensillen auf der antennengeißel von Lasius fuliginosus (Latr.) (Hymenoptera, Formicidae). Z. Morph. Tiere 73, 95-116. doi:10.1007/BF00280771

Dumpert, K., 1972b. Alarmstoffrezeptoren auf der Antenne von Lasius fuliginosus (Latr.) (Hymenoptera, Formicidae). Z. vergl. Physiologie 76, 403-425. doi:10.1007/BF00337782

Gill, K.P., van Wilgenburg, E., Macmillan, D.L., Elgar, M.A., 2013. Density of Antennal Sensilla Influences Efficacy of Communication in a Social Insect. The American Naturalist 182, 834-840. doi: $10.1086 / 673712$

Gosling, S.D., 1998. Personality dimensions in spotted hyenas (Crocuta crocuta). Journal of Comparative Psychology 112, 107-118. doi:10.1037/0735-7036.112.2.107

Greene, M.J., Gordon, D.M., 2007. Interaction rate informs harvester ant task decisions. BEHECO 18, 451-455. doi:10.1093/beheco/arl105

Hashimoto, Y., 1990. Unique Features of Sensilla on the Antennae of Formicidae (Hymenoptera). Applied Entomology and Zoology 25, 491-501. doi:10.1303/aez.25.491

Jandt, J.M., Robins, N.S., Moore, R.E., Dornhaus, A., 2012. Individual bumblebees vary in response to disturbance: a test of the defensive reserve hypothesis. Insect. Soc. 59, 313-321. doi:10.1007/s00040012-0222-1

Kamhi, J.F., Traniello, J.F.A., 2013. Biogenic Amines and Collective Organization in a Superorganism: Neuromodulation of Social Behavior in Ants. Brain Behav Evol 82, 220-236. doi:10.1159/000356091

Kleineidam, C., Romani, R., Tautz, J., Isidoro, N., 2000. Ultrastructure and physiology of the CO2 sensitive sensillum ampullaceum in the leaf-cutting ant Atta sexdens. Arthropod Structure and Development 29, 43-55. doi:10.1016/s1467-8039(00)00012-8

Nakanishi, A., Nishino, H., Watanabe, H., Yokohari, F., Nishikawa, M., 2009. Sex-specific antennal sensory system in the ant Camponotus japonicus: structure and distribution of sensilla on the flagellum. Cell Tissue Res 338, 79-97. doi:10.1007/s00441-009-0863-1

Page, R.E., Erber, J., Fondrk, M.K., 1998. The effect of genotype on response thresholds to sucrose and foraging behavior of honey bees (Apis mellifera L.). J Comp Physiol A 182, 489-500.

Page, R.E., Robinson, G.E., 1991. The Genetics of Division of Labour in Honey Bee Colonies, Advances in Insect Physiology, Advances in Insect Physiology. Elsevier. doi:10.1016/s0065-2806(08)60093-4

Pankiw, T., Page, R.E., Jr, 2000. Response thresholds to sucrose predict foraging division of labor in honeybees. Behav Ecol Sociobiol 47, 265-267. doi:10.1007/s002650050664

Pinter-Wollman, N., Hubler, J., Holley, J.-A., Franks, N.R., Dornhaus, A., 2012. How is activity distributed among and within tasks in Temnothorax ants? Behav Ecol Sociobiol 66, 1407-1420. doi: $10.1007 / \mathrm{s} 00265-012-1396-2$

Pinter-Wollman, N., Wollman, R., Guetz, A., Holmes, S., Gordon, D.M., 2011. The effect of individual variation on the structure and function of interaction networks in harvester ants. Journal of The Royal Society Interface 8, 1562-1573. doi:10.1098/rsif.2011.0059

Pruitt, J.N., Riechert, S.E., Jones, T.C., 2008. Behavioural syndromes and their fitness consequences in a socially polymorphic spider, Anelosimus studiosus. Animal Behaviour 76, 871-879. doi:10.1016/j.anbehav.2008.05.009

Ramirez-Esquivel, F., Leitner, N.E., Zeil, J., Narendra, A., 2017. The sensory arrays of the ant, Temnothorax rugatulus. Arthropod Structure and Development 46, 552-563. doi:10.1016/j.asd.2017.03.005

Ramirez-Esquivel, F., Zeil, J., Narendra, A., 2014. The antennal sensory array of the nocturnal bull ant Myrmecia pyriformis. Arthropod Structure and Development 43, 543-558. doi:10.1016/j.asd.2014.07.004

Ravary, F., Lecoutey, E., Kaminski, G., Châline, N., Jaisson, P., 2007. Individual Experience Alone Can Generate Lasting Division of Labor in Ants. Current Biology 17, 1308-1312. doi:10.1016/j.cub.2007.06.047 
Renthal, R., Velasquez, D., Olmos, D., Hampton, J., Wergin, W.P., 2003. Structure and distribution of antennal sensilla of the red imported fire ant. Micron 34, 405-413. doi:10.1016/S09684328(03)00050-7 exploitation in honeybees. Behav Ecol Sociobiol 64, 955-966. doi:10.1007/s00265-010-0911-6

Robinson, G.E., 1987. Modulation of alarm pheromone perception in the honey bee: evidence for division of labor based on hormonall regulated response thresholds. J Comp Physiol A 160, 613-619. doi:10.1007/BF00611934

Ruchty, M., Romani, R., Kuebler, L.S., Ruschioni, S., Roces, F., Isidoro, N., Kleineidam, C.J., 2009. The thermo-sensitive sensilla coeloconica of leaf-cutting ants (Atta vollenweideri). Arthropod Structure and Development 38, 195-205. doi:10.1016/j.asd.2008.11.001

Sharma, K.R., Enzmann, B.L., Schmidt, Y., Moore, D., Jones, G.R., Parker, J., Berger, S.L., Reinberg, D., Zwiebel, L.J., Breit, B., Liebig, J., Ray, A., 2015. Cuticular Hydrocarbon Pheromones for Social Behavior and Their Coding in the Ant Antenna. CellReports 12, 1261-1271. doi:10.1016/j.celrep.2015.07.031

Spaethe, J., Brockmann, A., Halbig, C., Tautz, J., 2007. Size determines antennal sensitivity and behavioral threshold to odors in bumblebee workers. The Science of Nature 94, 733-739. doi:10.1007/s00114007-0251-1

Vander Meer RK, Alonso LE (1998) Pheromone directed behavior in ants. In: Vander Meer, RK, Breed, M, Winston, M, Espelie, M (eds) Pheromone communication in social insects, Westview Press, Boulder, CO, pp 159-192

Villar, G., Baker, T., Patch, H., Grozinger, C., 2015. Neurophysiological mechanisms underlying sex- and maturation-related variation in pheromone responses in honey bees (Apis mellifera). J Comp Physiol A 1-9. doi:10.1007/s00359-015-1006-7

Waxman, H.K., Muscedere, M.L., Traniello, J.F.A., 2017. Behavioral Performance and Neural Systems Are Robust to Sensory Injury in Workers of the Ant $<\mathrm{b}><\mathrm{i}>$ Pheidole dentata $</ \mathrm{i}></ \mathrm{b}>$. Brain Behav Evol 89, 195-208. doi:10.1159/000470899

Weidenmüller, A., 2004. The control of nest climate in bumblebee (Bombus terrestris) colonies: interindividual variability and self reinforcement in fanning response. BEHECO 15, 120-128. doi:10.1093/beheco/arg101 